\title{
COMPARISON OF MAGNESIUM SULPHATE AS AN ADJUVANT TO LIGNOCAINE WITH LIGNOCAINE ALONE IN INTRAVENOUS REGIONAL ANAESTHESIA FOR UPPER LIMB SURGERY IN IMPROVING TOURNIQUET PAIN
}

1. FCPS (Anesthesia)

Associate Professor Anesthesia Shaikh Zayed Hospital, Lahore.

2. MS (Anesthesia)

Senior Registrar Anesthesia

Shaikh Zayed Hospital, Lahore

3. FCPS (Anesthesia)

Senior Registrar Anesthesia

Jinnah Hospital, Lahore.

Correspondence Address: Dr. Hajra Shuja

Senior Registrar Anesthesia

Jinnah Hospital, Lahore.

hajrashuja1@gmail.com

Article received on:

21/04/2020

Accepted for publication:

$00 / 00 / 2020$

\begin{abstract}
Syed Mehmood Ali', Sadaf Bokhari², Hajra Shuja ${ }^{3}$
ABSTRACT... Objectives: To compare mean time of the first analgesic requirement with the Magnesium sulfate with lignocaine and lignocaine alone under intravenous regional anaesthesia for upper limb surgery. Study Design: Randomized Controlled Trial. Setting: Operative Rooms of Shaikh Zayed Hospital, Lahore. Period: October 2, 2018 to April 2, 2019. Material \& Methods: A total of 150 (75 subjects per group) were selected that fulfilled the inclusion criteria. Those subjects were allocated by the use of the tables to two separate anesthetic regimes. Lignocaine plus magnesium sulphate was given to experimental group $(A)$ as an adjunct and control group (B) was given simple intravenous regional anesthesia (IVRA) with lignocaine. Mean Atrial Pressure, Heart Rate, and SpO2 were tracked every two minutes after start of anesthesia before and after use of the tourniquet. All the patients will be counseled to report if they experience tourniquet pain. When patients complained of tourniquet pain it was assessed on VAS of I-10 and patient was given analgesia if pain $>3$ on VAS. The data were collected and analyzed in SPSS v25.0. The median time for analgesics was used in both groups for the analysis of the independent t-test. A p-value of 0.05 was estimated significant. Results: Total 150 (75 in each group) patients were enrolled. Mean time to first analgesic requirement is greater with the Magnesium sulfate with lignocaine and lignocaine alone in patients undergoing upper $\operatorname{limb}$ surgery under intravenous regional anaesthesia $51.9 \pm 4.2$ minutes vs. $32.1 \pm 4.4$ minutes $(p=0.000)$. Conclusion: The findings indicate that the tourniquet pain is reduced by adding magnesium sulphate as an adjuvant to lignocaine.
\end{abstract}

Key words: Intravenous Regional Anesthesia, Lignocaine, Magnesium Sulfate, Postoperative Analgesia.

Article Citation: Ali SM, Bokhari S, Shuja H. Comparison of magnesium sulphate as an adjuvant to lignocaine with lignocaine alone in intravenous regional anaesthesia for upper limb surgery in improving tourniquet pain. Professional Med J 2020; 27(6):1311-1315. DOI: 10.29309/TPMJ/2020.27.06.4740

\section{INTRODUCTION}

Intravenous Regional Anesthesia (IVRA) is one of the easiest, simplest and economical type of regional anesthesia, and has the most popular results. Nevertheless, intravenous regional anesthesia(IVRA) was restricted by tourniquet pain and its failure to provide post-operative analgesia. ${ }^{1}$ In order to increase block consistency, extend post-deflation analgesia and decrease tourniquet pain, various additives were combined with local anesthetics, with minimal efficacy. ${ }^{2}$

The mechanism of the analgesic effects of magnesium is not clear, but interaction with calcium channels and N-methyl-d-aspartate receptors tend to play an important role. $^{3}$
Magnesium has proven effective in reducing the pain associated with transmission. Magnesium is used empirically for several years as a medical treatment for eclampsia and intraoperative or post-operative analgesia. ${ }^{4-5}$

IVRA is routinely used as a one of the good option for managing upper limb neuropathic pain and found that adding magnesium to Lignocaine increases block efficiency enhances analgesia and decreases the overall failure rate. However, the drawback of this procedure was pain with magnesium injection, with similar findings in other reports. ${ }^{6}$ Multiple local anesthetics for intravenous regional anesthesia have been combined to increase block consistency, analgesia and 
decrease tourniquet pain. ${ }^{1,7}$ Magnesium sulphate is one possible additive.

In a randomized controlled trial, visual analog scale (VAS) was lower in group A at 20, 30, 40 and 50 min after inflation with the tourniquet $(P$ $<0.05)$. The need for analgesics during surgery was reduced in group $A(p<0.05)$. Excellence in anesthesia was slightly higher in group $A$ $(p<0.05)$, as calculated by the anesthesiologist and surgeon. The first analgesic criterion was $53.7 \pm 6.9 \mathrm{~min}$ in group $\mathrm{A}$, and $40.7 \pm 14.5 \mathrm{~min}$ in group $B(p<0.05) .{ }^{7}$ The purpose of this is to evaluate the effect of magnesium sulphate when added as adjuvant to lignocaine in intravenous regional anesthesia (IVRA) for elective upper limb surgery in reducing tourniquet pain to improve patient's compliance. If the mean time to first analgesic requirement is less with combination of magnesium sulphate and lignocaine, then use of magnesium as an additive with local anesthesia can performed, so that good quality block can be offered for these procedures.

\section{MATERIAL \& METHODS}

The study was conducted at Department of Anesthesia, Shaikh Zayed Hospital, Lahore from October 2, 2018 to April 2, 2019. After taking approval from hospital ethical committee and written informed consent from patients, randomized controlled trial was conducted. The inclusion criteria was ASA status I and II patients, age between 18-60 years of both genders, elective procedures, hand and fore arm surgeries. The exclusion criteria was known history of allergy to Lignocaine, Contraindications of $\mathrm{Mg}$. e.g. peripheral neuropathy motor or sensory (on the basis of history) and Contraindications of tourniquet e.g. known case of Raynaud's disease and sickle anemia (on history).

Sample size 150 cases; 75 cases in each group was calculated with 95\% confidence level with $80 \%$ power of test and taking magnitude of mean time of first analgesia requirement i.e. $53.75 \pm 6.94$ min in lignocaine with magnesium sulphate group and $40.76 \pm 14.55 \mathrm{~min}$ in lignocaine group in patients of intravenous regional anesthesia. ${ }^{7}$ Total 150 (75 in each group) subjects those fulfilling the inclusion criteria were selected for the study. Those subjects were allocated by the use of the tables to two separate anesthetic regimes. Lignocaine plus magnesium sulphate was administered to the experimental group (A) and control group (B) was given simple lignocaine IVRA. Mean blood pressure (MAP), oxygen saturation $\left(\mathrm{Spo}_{2}\right)$ and Heart rate $(\mathrm{HR})$ were observed in the operating room. Before the anesthetic block was formed, two cannulas were placed; one in the vein on the surgical hand and the other in the opposite side.

Operative arm was stretched by an Esmarch bandage exsanguinatcd for three minutes. Two pneumatic tourniquets were applied and the proximal cuff was inflated with $100 \mathrm{mmHg}$ over Systolic blood pressure. By inspection, the circulatory isolation was tested, lack of pulse and on surgical side, inability to trace pulse oximetry. Intravenous regional anesthesia was achieved by using $20 \mathrm{ml}$ of lignocaine $1 \%$ diluted in group $\mathrm{B}(\mathrm{N}=75)$ with saline of $20 \mathrm{ml}$ to $40 \mathrm{ml}$, or $7.5 \mathrm{ml}$ of $1.5 \mathrm{~g}$ magnesium sulfate $20 \%$ plus $20 \mathrm{ml}$ of lignocaine $1 \%$ diluted in group A with saline 12.5 $\mathrm{ml}$ to $40 \mathrm{ml}$.

An anesthesiologist oblivious to the medication administered the injection in ninety seconds, and followed the patient. After the success of sensory and motor blocks, surgery is started, when patient complains of pain,the distal cuff is inflated and proximal cuff is deflated slowly. Heart rate and $\mathrm{SpO}_{2}$ were tracked at every two minutes after the start of anesthesia, before and after use of tourniquet. All the patients will be counseled to report if they experience tourniquet pain. When patients complained of tourniquet pain it was assessed on VAS of I-10 and patient was given analgesia if pain $>3$ on VAS. Then time from administration of analgesia till first requirement of analgesia was calculated in minutes.

Quantitative variables such as age and time of first analgesic demand were measured in the form of Mean and standard deviation. The data was obtained and analyzed in SPSS v25.0. Qualitative variables such as gender, frequency and percentages are measured. The mean time for analgesics was used in both groups for the analysis of the independent t-test. A p-value of 
0.05 was estimated significant.

\section{RESULTS}

Total 150 patients were enrolled in this study. Mean time to first analgesic requirement is greater with the combination of magnesium sulphate with lignocaine than lignocaine alone in patients undergoing Upper limb surgery under intravenous regional anaesthesia $51.9 \pm 4.2$ minutes vs. $32.1 \pm 4.4$ minutes $(p=0.000)$.

\begin{tabular}{|l|c|c|c|}
\hline & \multicolumn{2}{|c|}{ Groups } & \multirow{2}{*}{ Gender } \\
\cline { 1 - 3 } & $\begin{array}{c}\text { Group A } \\
\text { Lignocaine } \\
\text { plus } \\
\text { magnesium } \\
\text { sulphate }\end{array}$ & $\begin{array}{c}\text { Group B } \\
\text { Lignocaine } \\
\text { alone }\end{array}$ & Total \\
\hline Male & $51(68.0 \%)$ & $57(76.0 \%)$ & $108(72.0 \%)$ \\
\hline Female & $24(32.0 \%)$ & $18(24.0 \%)$ & $42(28.0 \%)$ \\
\hline Total & $75(100.0 \%)$ & $75(100.0 \%)$ & $150(100.0 \%)$ \\
\hline
\end{tabular}

Table-I: Comparison of gender distribution in both groups

\begin{tabular}{|c|c|c|c|}
\hline \multirow[b]{2}{*}{ Age Groups } & \multicolumn{2}{|c|}{ Groups } & \multirow[b]{2}{*}{ Total } \\
\hline & $\begin{array}{l}\text { Group A } \\
\text { Lignocaine } \\
\text { plus } \\
\text { magnesium } \\
\text { sulphate }\end{array}$ & $\begin{array}{c}\text { Group B } \\
\text { Lignocaine } \\
\text { alone }\end{array}$ & \\
\hline $18-30$ years & 24 (32.0\%) & 25 (33.3\%) & $\begin{array}{c}49 \\
(32.7 \%)\end{array}$ \\
\hline $31-45$ years & 23 (30.7\%) & 31 (41.3\%) & $\begin{array}{c}54 \\
(36.0 \%)\end{array}$ \\
\hline$>45$ years & 28 (37.3\%) & 19 (25.3\%) & $\begin{array}{c}47 \\
(31.3 \%)\end{array}$ \\
\hline Total & 75 (100\%) & 75 (100\%) & $\begin{array}{c}150 \\
(100 \%)\end{array}$ \\
\hline
\end{tabular}

Table-II. Comparison of age distribution in both

$$
\text { groups }
$$

\section{DISCUSSION}

In the present study, the mean time to first rescue analgesia in Group-A using magnesium sulphate + lignocaine was significantly more than in Group-B using lignocaine alone. The mean number of rescue analgesics required in Group-A was also less than in Group-B. Similar findings have been obtained from Turanet al. ${ }^{8}$ who concluded that magnesium sulphate has enhanced anesthesia and analgesia consistency in intravenous regional anesthesia (IVRA) by incorporating lignocaine additives. In the magnesium sulfate group, time to first rescue analgesia was significantly higher than in the control group. For the first post-operatory six hour in the control group, VAS was higher.

The consumption of rescue analgesics was significantly less in the magnesium sulfate group. Similarly, Bansalet al. ${ }^{9}$ found that magnesium sulphate at a dose of $1.5 \mathrm{~g}$ added to lignocaine prolonged postoperative analgesia, with no side effects. In order to prolong post-operative analgesia, anesthesiologists usually add an adjuvant to lignocaine. ${ }^{10}$ Clinical studies have shown that opioids as adjuvant to lignocaine to IVRA improved sensory block and postoperative analgesia. ${ }^{11-12}$ Several laboratory and clinical studies have shown that magnesium sulphate might have a local anesthetic type effect. ${ }^{13-14}$ However, Acalovschi et al. showed that magnesium sulphate does not have a local anesthetic effect when used as a sole drug for IVRA, but could modify the action of local anesthetic when used as an adjuvant. ${ }^{15}$

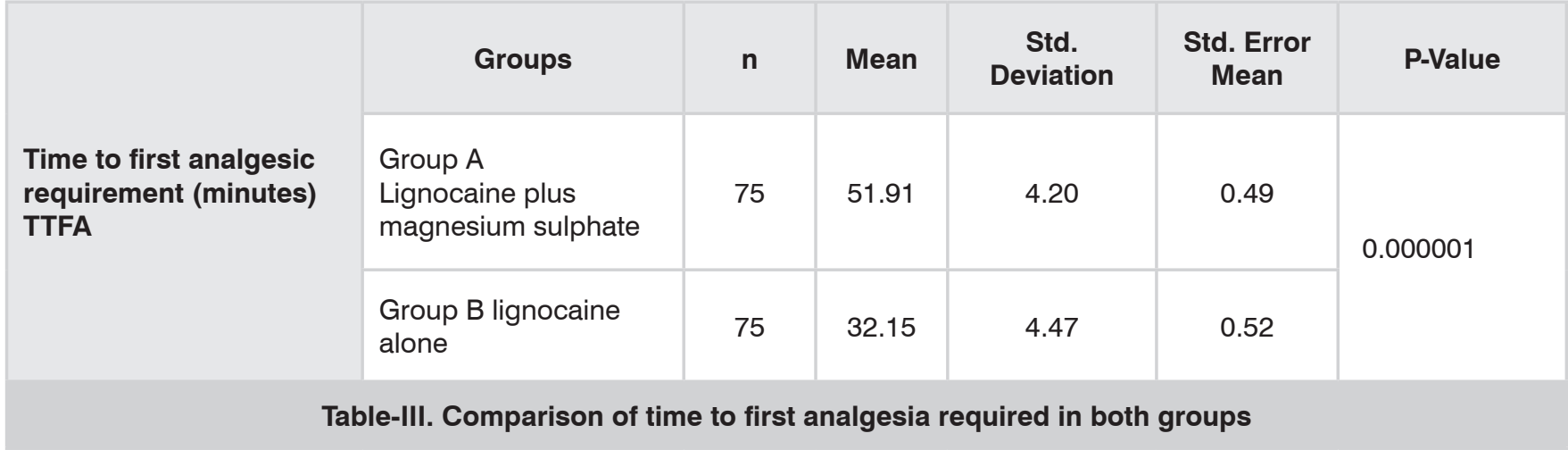


In another study by Goel Sunita et al., magnesium sulphate was more effective than ketolorac as an adjuvant to IVRA without opioid related side effects. ${ }^{16}$ Like our study, they found that magnesium sulphate, as an adjuvant to IVRA, reduces post-operative pain intensity and analgesic requirement in the post-operative period. Furthermore, magnesium sulphate in comparison to placebo onset of sensory block may be due to its local anesthetic effect. Turan et al., in their study, found that magnesium sulphate in comparison to placebo has effective control of postoperative pain. ${ }^{17}$

However, El-Tahawy et al., in a study, compared dexmedetomidine and Magnesium sulphate as an adjuvant to IVRA and found that magnesium sulphate was not effective as an adjuvant to IVRA in control of tourniquet pain and decreasing postoperative pain intensity. ${ }^{18}$ Another study by $\mathrm{Nasr}$ et al., revealed that tramadol and dexmedetomidine, as an adjuvant to IVRA, caused delayed onset of post-operative pain, and less post-operative consumption of supplementary analgesia. ${ }^{19}$ In our study magnesium sulphate as an adjuvant was effective in reduction of postoperative pain intensity and delayed onset of post-operative pain.

\section{CONCLUSION}

The findings indicate that the tourniquet pain is reduced by adding magnesium sulphate as an adjuvant to lignocaine.

\section{Copyright(C)}

\section{REFERENCES}

1. Turan A, Memi D, Karamanlio B, Gtiler T, Pamukeu Z. Intravenous Regional Anesthesia Using Lidocaine and Magnesium Anesth. Analg 2015;100:1189-92.

2. Narang S, Dali JS, Agarwal M, Garg R. Evaluation of the efficacy of magnesium sulphate as an adjuvant to lignocaine for intravenous regional anaesthesia for upper limb surgery. Anaesth Intensive Care 2018;36:840-4.

3. Apan A, Buyukkocak U, Ozcan S, Sari E, Basar H. Postoperative magnesium sulphate infusion reduces analgesic requirements in spinal anaesthesia. Eur $\mathrm{J}$ Anaesthesiol 2014;21:1766-9.
4. Hwang JY, Na HS, Jeon YT, RY, Kim CS, Do SH. IV infusion of magnesium sulphate during spinal anaesthesia improves postoperative analgesia. $\mathrm{Br} \mathrm{J}$ Anaesth 2016;96:247-52.

5. Kara H, Sahin N, Ulusan V, Aydogdu T. Magnesium infusion reduces perioperative pain. Eur J Anaesthesiol 2016;19:52-6.

6. Choyce A, Peng P. A systematic review of adjuncts for intravenous regional anesthesia for surgical procedures. Can J Anaesth 2016;49:32-45.

7. Kashefi P, Montazeri K, Honamiand A, Moradi A and Masoomi SG. Adding magnesium to lidocaine for intravenous regional anesthesia. J Res Med Sci 2018;13(3):108-114.

8. Turan A, Memis D, Karamanlioglu B, Güler T, Pamukçu Z. Intravenous regional anesthesia using lidocaine and magnesium. Anesth Analg 2015;100:1189-92.

9. Bansal P, Baduni N, Bhalla J, Mahawar B. A comparative evaluation of magnesium sulphate and nitroglycerine as potential adjuncts to lidocaine in intravenous regional anaesthesia. Int J Crit Sci 2015;5:27-31.

10. Imani F. Postoperative pain management. Anesth Pain Med. 2011;1(1):6-7.

11. Imani F, Entezary SR, Alebouyeh MR, Parhizgar S. The maternal and neonatal effects of adding tramadol to $2 \%$ lidocaine in epidural anesthesia for cesarean section. Anesth Pain Med. 2011;1(1):25-9.

12. Ramaiah VK, Trikha A, Mohan V, Saksena R. Comparison of Parecoxib and Butorphanol as Adjuvant to Lidocaine in Intravenous Regional Anaesthesia. Anesthesiology. 2006;105:1129.

13. Kargi E, Babuccu O, Altunkaya H, Hosnuter M, Ozer $\mathrm{Y}$, Babuccu $\mathrm{B}$, et al. Tramadol as a local anaesthetic in tendon repair surgery of the hand. $\mathrm{J}$ Int Med Res. 2008;36(5):971-8.

14. Altunkaya $\mathrm{H}$, Ozer $\mathrm{Y}$, Kargi E, Ozkocak I, Hosnuter M, Demirel CB, et al. The postoperative analgesic effect of tramadol when used as subcutaneous local anesthetic. Anesth Analg. 2004;99(5):1461-4.

15. Acalovschi I, Cristea T, Margarit S, Gavrus R. Tramadol added to lidocaine for intravenous regional anesthesia. Anesth Analg. 2001;92(1):209-14.

16. Goel Sunita N, Daftary Swati R, Pantavaidya Shanti H. Intravenous Regional Anaesthesia Using Tramadol Hydrochloride and Ketorolac: A Double Blind Controlled Study. Indian J Anaesth. 2002:370. 
17. Turan A, Memis D, Karamanlioglu B, Guler T, Pamukcu $Z$. Intravenous regional anesthesia using lidocaine and magnesium. Anesth Analg. 2005;100(4):1189-92.

18. El-Tahawy M, Shaaban AR, Ahmad A. Comparison between dexmedetomidine and magnesium sulfate as adjuvants for intravenous regional anesthesia. Ain-Shams J Anaesthesiol. 2015;8(1):129.
19. Nasr YM, Waly SH. Lidocaine-tramadol versus lidocainedexmedetomidine for intravenous regional anesthesia. Eg J Anaesth. 2012;28(1):37-42.

\begin{tabular}{|c|c|c|c|}
\hline \multicolumn{4}{|c|}{ AUTHORSHIP AND CONTRIBUTION DECLARATION } \\
\hline Sr. \# & Author(s) Full Name & Contribution to the paper & Author(s) Signature \\
\hline 1 & Syed Mehmood Ali & Concept. & M.A.su \\
\hline 2 & Sadaf Bokhari & Data collection. & Sodal. \\
\hline 3 & Hajra Shuja & Review of writing. & bigheyn. \\
\hline
\end{tabular}

